\title{
LICENSURE PORTABILITY: ASSURING ACCESS TO QUALITY CARE IN PHYSICAL THERAPY
}

\author{
MARK LANE, PT, MPT \\ Federation of STATE BoArds of Physical Therapy, Alexandria, Virginia, USA
}

\section{ABSTRACT}

The concurrent circumstances of an increasingly mobile workforce, disparities in access to healthcare, and the ability to deliver care through technology (e.g., telehealth) present the need and the opportunity for practice across state borders. Over the past four years, the Federation of State Boards of Physical Therapy (FSBPT) has explored professional licensure models that will allow cross border practice. This paper reviews FSBPT's exploratory process and describes some of the advantages of an interstate compact. It concludes that if agreement among state licensing boards can be achieved, a compact could serve as a viable means to increase patient access to quality physical therapy care.

Keywords: Licensure, physical therapy, telehealth, telerehabilitation

The Federation of State Boards of Physical Therapy (FSBPT) is a membership organization whose mission is to protect the public by providing service and leadership that promotes safe and competent physical therapy practice. FSBPT's membership is comprised of the 53 jurisdictional licensing boards in the United States.

FSBPT and its member jurisdictions have of late, become very interested in the ability of licensees to move and practice with ease across state lines. Attention to this issue has been precipitated by two deepening challenges: increasing workforce expectations for employee mobility, and uneven access to healthcare. FSBPT further recognized that such challenges are global in nature, transcending state and national boundaries. State and provincial based countries were not only dealing with portability within their own countries but were beginning to explore mutual recognition between countries (Australia Health Practitioner Regulation Agency, 2013; Physiotherapy Board of Australia, 2014; Government of Canada, 2013; Gouvernement du Québec, 2013).

FSBPT's attention to interstate practice was also fueled by concurrent technological advances. Innovative technologies were developing that increasingly allowed practice that did not require the practitioner and the consumer to be in the same location. This trend allows more access to remote areas as well as access to specialists who may not necessarily be located in proximity to the patient.

FSBPT recognized that the current model of statebased regulation, which had historically served the public well, needed to be modified. Licensure was designed to protect the public, however, the limitations in portability and ability to practice across state lines was preventing access and potentially good care. There was, moreover, no interest on the part of FSBPT to eliminate statebased regulation, but instead, to change how it worked to allow increased mobility of licensees with the result of extending access to high quality care. There was a concrete realization that telehealth was a viable delivery mode for healthcare and that the current licensure system was an impediment to the use of telehealth in physical therapy. This is a story of learning, discussing and sharing between multiple professions as well as international physiotherapy regulators.

In 2010, FSBPT's delegate assembly, representing the 53 member jurisdictions, asked FSBPT to review the nursing licensure compact as a potential model for improving portability. The National Council of State Boards of Nursing (NCSBN) has been a leader in dealing with the licensure portability challenge. NCSBN developed a nursing compact over 10 years ago and currently has 24 participating states (Nurse Licensure Compact Administrators, 2012). It allows a nurse licensed in one jurisdiction to practice in the other participating compact states provided the nurse meets certain requirements.

In brief, interstate compacts are not a new concept but have been around since the inception of this country (de Golian, 2014). The driver's license is a readily understandable example of how a licensure compact might work. Once a resident of the United States has a driver's license in one state, he or she is able to drive in any of the 50 states or territories. This is the result of an interstate compact.

FSBPT's report back to its delegate assembly recognized the benefits of the nursing compact but did not recommend pursuing any portability initiative until further exploration of alternate options was completed. 
Concerns with a licensure compact included: 1) the resistance within some states to implement the nursing compact which resulted in a slow implementation, 2) the need for an effective way to deal with licensees who violated regulations within a jurisdiction, and 3) how the disciplinary process would work when a licensee was authorized to practice in multiple jurisdictions.

In 2011 and 2012, the FSBPT explored multiple options to ease the process of physical therapists getting licensed and practicing in multiple states. Such approaches as an expedited license, a credentials verification/storage service and a uniform application were considered.

In spring 2013, FSBPT noted that the Federation of State Medical Boards (FSMB) Delegate Assembly passed an initiative to explore a licensure compact for licensure of physicians (Federation of State Medical Boards, 2013). This caused the FSBPT to refocus on the concept of a compact. It made sense that regulated healthcare professions would approach and solve the portability issue in a similar manner versus each profession developing different approaches. FSBPT was intrigued. In its explorations, FSBPT learned a couple of key points related to interstate compacts:

1. A compact can be designed to meet the needs of the particular profession and does not have to be based on any other profession's model. This concept opened the door for learning and gaining insight from other professions who were ahead of FSBPT in implementing a compact.

2. Since establishing a compact was ultimately a legislative process, there was potential momentum that could be gained via multiple professions developing a compact. The state legislatures would already be exposed to the licensure compact as a means to deal with portability.

3. There were multiple other professions, beyond nursing, either developing a compact or exploring a compact.

4. The Council of State Governments (CSG), a non-partisan group, was available as a resource. CSG had experts in the implementation and running of state compacts. This gave them both a historical perspective and governmental contacts (Council of State Governments, 2011; de Golian, 2014).

The FSBPT Board of Directors brought the concept of a licensure compact for physical therapy to its Leadership Issues Forum (LIF). The LIF is a meeting of the leadership of the organization, including delegate representatives from its member states. Current regulatory issues and topics are discussed and explored in LIF.

LIF participants were very favorable to the concept of a licensure compact for physical therapy. Therefore, FSBPT next sought and obtained support from its delegate assembly for the initial exploration of a physical therapy compact. Conceptual discussions also began with other stakeholders including the professional association, the American Physical Therapy Association (APTA).
Currently, FSBPT is in the initial portion of the advisory phase of developing a compact. This phase includes meetings that will include important stakeholders, including the public, to determine if some agreement can be achieved on a model for a compact. If agreement can be reached, the group will also make recommendations on how the compact will operate. The next step, provided FSBPT moves forward, would be the drafting phase wherein the statute language would be developed. The drafting phase is followed by the implementation phase in which states begin the legislative process for implementing the compact. The intent of the compact will be to address issues of practice across state lines including via telehealth technologies to improve access to consumers.

To modify a historical model of licensure that has served the public well for many years will not be easy but, in an increasingly global world, interstate licensing agreements provide a means to ensure access to high quality care, while promoting continuity between patients and healthcare providers. FSBPT is very excited about the possibilities of bringing the state-based licensure system up to date in order to meet the needs of consumers of physical therapy within the US. It hopes that other professions will also seize this opportunity to develop a more uniform approach to the issue of portability and practice across state lines. 


\section{REFERENCES}

1. Australia Health Practitioner Regulation Agency. (2013). 2013/14 Health profession agreement-Physiotherapy Board of Australia and AHPRA. Retrieved from http:// www.ahpra.gov.au/Publications/Health-professionagreements.aspx

2. Council of State Governments. (2011). The National Center for Interstate Compacts (NCIC): About. Retrieved from http://www.csg.org/NCIC/about.aspx

3. de Golian, C. (2014). Interstate compacts: What was old is new again. Retrieved from http://knowledgecenter.csg. org/kc/content/interstate-compacts-what-was-old-newagain

4. Federation of State Medical Boards. (2013). Interstate compact for physician licensure moves forward with consensus principles. Retrieved from http://www.fsmb. org/pdf/nr_interstate_compact.pdf

5. Gouvernement du Québec. (2013). Québec-France agreement on the mutual recognition of professional qualifications. Retrieved from http://www.mrifce. gouv.qc.ca/en/grands-dossiers/reconnaissancequalifications/entente-quebec-france

6. Government of Canada. (2013). Labour mobility. Retrieved from http://www.esdc.gc.ca/eng/jobs/credential_ recognition/labour_mobility/index.shtml

7. Nurse Licensure Compact Administrators. (2012). Nurse Licensure Compact (NLC) fact sheet for legislators. Retrieved from https://www.ncsbn.org/2012_NLCA_ factsheet_legislators.pdf

8. Physiotherapy Board of Australia. (2014). Meeting of the Physiotherapy Board of Australia -28 February 2014. Retrieved from http://www.physiotherapyboard.gov.au/ News/2014-03-06-communique.aspx 
